\title{
A new sheep shed which overcomes heat stress and disease losses in the Malaysian humid tropics
}

\author{
MP Davis, MA Rajion, CTNI Fatimah \\ Faculty of Veterinary Medicine and Animal Science, Universiti Pertanian Malaysia, \\ 43400 UPM Serdang, Selangor, Malaysia
}

\begin{abstract}
Sheep imported to the Malaysian humid tropics adapt very poorly under grazing conditions. They suffer from heat stress, sub-maintenance nutrition and extremely high mortalities, Davis and Rajion (1990, Proc Malaysian Soc Anim Prod Ann Conf, 275-278). Indigenous sheep also suffer from the same biological constraints but are much better adapted. However, their low growth rates $(25.50 \mathrm{~g} / \mathrm{d})$ and low mature body weight $(25 \mathrm{~kg})$ are undesirable for meat production. Our original experimental sheep shed with open sides and raised wooden slatted floor partly overcame heat stress and most of the disease problems except pneumonia.
\end{abstract}

Modifications incorporated into our new sheep shed $(12 \mathrm{~m} \times 30 \mathrm{~m})$ have further improved health and production. Increasing the height of the shed by $1 \mathrm{~m}$ to $5.7 \mathrm{~m}$, raising the floor height from $1.5 \mathrm{~m}$ to $1.9 \mathrm{~m}$ and changing the asbestos roof to a higher pitched aluminium roof prevented the heat accumulation experienced with the original sheep shed. Although temperatures just below the noninsulated aluminium roof reached $42^{\circ} \mathrm{C}$, the temperature at sheep level never exceeded ambient (maximum $35^{\circ} \mathrm{C}$ ) due to efficient crossflow ventilation. Uninterrupted air flow was permitted by locating the sheep shed away from buildings, trees and shrubs. There was no indication of heat stress; respiration rates and rectal temperatures were within normal range and growth rates to early maturity averaged 200 $\mathrm{g} / \mathrm{d}$ for six different breeds of crossbred sheep. In contrast the original sheep shed with its lower asbestos roof overheated during daylight hours, (Davis et al, 1994, Proc 2nd Symposium on Sheep Production in Malaysia, 111-112) which probably caused mild heat stress, given the high humidity, and contributed to the less than optimal growth rate of $149 \mathrm{~g} / \mathrm{d}$, (Davis et al, 1991, Proc 3rd International Symposium on the Nutrition of Herbivores, Malaysia, 83).

The principal causes of death of imported Australian sheep grazed in open pastures in
Malaysia were pneumonia, haemonchosis and acute starvation which together accounted for three quarters of the $10 \%$ per month death rate (Fatimah et al, 1992, J Vet Malaysia, 4 (2), 8796). Housing sheep above ground was found to be highly beneficial for their health. The death rate was reduced to $1.5 \%$ per month when grazed sheep were transferred to the original shed with a raised wooden slated floor and supplied with good nutrition. This improved husbandry prevented most of the health problems except pneumonia which continued to be the major cause of death, albeit at a lower rate. Installation of a wire mesh floor $(8 \mathrm{~mm}$ diameter galvanised iron with $12 \mathrm{~mm}$ gaps) in the new sheep shed abolished death from pneumonia altogether. Indeed, in the 20 months operation of the new sheep shed with its metal floor, no death from disease occurred at all whereas $30 \%$ would have been expected if the sheep had remained in the original shed. The main reason for the improved health of the sheep was considered to be due to high standard of hygiene resulting from the wire mesh floor which was largely self-cleaning. The cost of the sheep shed if constructed entirely of steel has been calculated to be not more than the cheapest buildings in Malaysia, namely $\mathrm{RM} 215 / \mathrm{m}^{2}$.

In conclusion, the new sheep shed protects sheep at an economic cost from the harsh humid tropical environment of Malaysia and its severe parasite and disease burden. This shed allows sheep to be fed concentrates, cash crops or cut and carry herbage without having to endure the heat stress and diseases normally experienced by grazing sheep in the humid tropics. Under these improved conditions, all breeds of sheep tested, including temperate and tropical sheep and their crossbreeds, when fed a nutritionally adequate diet performed better than predicted by the ARC energy gain equations (Davis et al, 1994, Proc 7th ASAP Animal Science Congress, Bali, 391-392). 